\title{
Impact of obesity on perinatal outcomes among asthmatic women
}

\author{
Meggie Thuot B Pharm¹, Marc-André Coursol B Pharm ${ }^{1}$, Sonia Nguyen B Pharm¹, Vanessa Lacasse-Guay B Pharm¹, \\ Marie-France Beauchesne Pharm $\mathrm{D}^{1,2}$, Anne Fillion $\mathrm{MSc}^{1,3}$, Amélie Forget $\mathrm{MSc}^{1,3}$, \\ Fatima-Zohra Kettani $\mathrm{MSc}^{1,3}$, Lucie Blais $\mathrm{PhD}^{1,2,3}$
}

M Thuot, M-A Coursol, S Nguyen, et al. Impact of obesity on perinatal outcomes among asthmatic women. Can Respir J 2013;20(5):345-350.

BACKGROUND: Only one study has investigated the combined effect of maternal asthma and obesity on perinatal outcomes; however, it did not consider small-for-gestational age and large-for-gestational age infants.

OBJECTIVES: To examine the impact of obesity on perinatal outcomes among asthmatic women.

METHODS: A cohort of 1386 pregnancies from asthmatic women was reconstructed using three of Quebec's administrative databases and a questionnaire. Women were categorized using their prepregnancy body mass index. Underweight, overweight and obese women were compared with normal weight women. The primary outcome was the birth of a small-forgestational-age infant, defined as a birth weight below the 10th percentile for gestational age and sex. Secondary outcomes were large-for-gestationalage infants (birth weight $>90$ th percentile for gestational age) and preterm birth ( $<37$ weeks' gestation). Logistic regression models were used to obtain the ORs of having small-for-gestational-age infants, large-for-gestational-age infants and preterm birth as a function of body mass index.

RESULTS: The proportions of underweight, normal weight, overweight and obese women were $10.8 \%, 53.3 \%, 19.7 \%$ and $16.2 \%$, respectively. Obese asthmatic women were not found to be significantly more at risk for giving birth to small-for-gestational-age infants (OR 0.6 [95\% CI 0.4 to 1.1]), large-for-gestational-age infants (OR 1.2 [95\% CI 0.7 to 2.2]) or having a preterm delivery (OR 0.7 [95\% CI 0.4 to 1.3]) than normal-weight asthmatic women.

CONCLUSIONS: No significant negative interaction between maternal asthma and obesity on adverse perinatal outcomes was observed.

Key Words: Asthma; Large-for-gestational-age; Obesity; Pregnancy; Preterm birth; Small-for-gestational-age

A sthma and obesity are two common diseases among pregnant women, with an estimated prevalence of $8 \%$ and $10 \%$, respectively $(1,2)$. Independently, these diseases are known to have an impact on perinatal outcomes $(1,2)$. In a recent meta-analysis of 40 studies, women with asthma were found to have higher risks of pregnancy complications including small-for-gestational-age (SGA) and preterm birth (3). More specifically, several studies have reported a strong association between poor asthma control and adverse perinatal outcomes (4-7). Moreover, studies have reported an increased risk of preterm birth among women with severe asthma or women taking oral corticosteroids (OCS) during pregnancy, and an increased risk of SGA birth among asthmatic women with daily symptoms $(7,8)$. Another study also reported a significant association between lower pulmonary function (according to forced expiratory volume in $1 \mathrm{~s}\left[\mathrm{FEV}_{1}\right]$ ) and an increased risk of prematurity (5).

Similar to asthma, obesity is associated with complications in pregancy; however, these complications seem to go in the opposite direction. In fact, several studies have reported that obese pregnant women

\section{Les conséquences de l'obésité sur les issues périnatales des femmes asthmatiques}

HISTORIQUE : Une seule étude a porté sur l'effet combiné de l'asthme et de l'obésité de la mère sur les issues périnatales. Cependant, elle ne tenait pas compte des nourrissons petits ou gros par rapport à leur âge gestationnel.

OBJECTIFS : Examiner les conséquences de l'obésité sur les issues périnatales des femmes asthmatiques.

MÉTHODOLOGIE : Les chercheurs ont reconstruit une cohorte de 1386 grossesses de femmes asthmatiques à l'aide de trois bases de données administratives du Québec et d'un questionnaire. Ils les ont classées d'après leur indice de masse corporelle avant la grossesse. Ils ont comparé les femmes en insuffisance pondérale, qui faisaient de l'embonpoint et qui étaient obèses avec les femmes de poids normal. L'issue primaire était la naissance d'un nourrisson petit par rapport à son âge gestationnel, défini comme un poids situé sous le $10^{\mathrm{e}}$ percentile par rapport à l'âge gestationnel et au sexe. Les issues secondaires étaient la naissance d'un nourrisson gros par rapport à son âge gestationnel (poids supérieur au $90^{\mathrm{e}}$ percentile par rapport à l'âge gestationnel) ou d'un nourrisson prématuré (moins de 37 semaines de grossesse). Ils ont utilisé des modèles de régression logistique pour obtenir les risques relatifs rapprochés d'avoir un nourrisson petit par rapport à son âge gestationnel, gros par rapport à son âge gestationnel ou prématuré en fonction de l'indice de masse corporelle.

RÉSULTATS : La proportion de femmes en insuffisance pondérale, de poids normal, faisant de l'embonpoint ou obèses s'établissait à 10,8\%, $53,3 \%, 19,7 \%$ et $16,2 \%$, respectivement. Les femmes asthmatiques obèses n'étaient pas nettement plus à risque d'accoucher d'un nourrisson petit par rapport à son âge gestationnel (RRR 0,6 [95 \% IC 0,4 à 1,1]), gros par rapport à son âge gestationnel (RRR 1,2 [95\% IC 0,7 à 2,2]) ou prématuré (RRR 0,7 [95\% IC 0,4 à 1,3]) que les femmes asthmatiques de poids normal. CONCLUSIONS : On n'a observé aucune interaction négative d'importance entre l'asthme et l'obésité de la mère sur les issues périnatales négatives.

have a higher risk for macrosomia, and large-for-gestational-age (LGA) infants and a lower risk for SGA infants (9-12). However, the association between obesity and preterm birth is less clear: some studies found a higher risk $(10,11)$ and others a lower risk $(9,12)$. Apart from this, an increasing body of data supports the hypothesis that obesity may worsen asthma control $(13,14)$.

Given the possible interaction between asthma and obesity, we hypothesized whether pregnant women with asthma and obesity were more at risk of adverse perinatal outcomes than pregnant women with asthma and a normal weight. To our knowledge, only one study (Hendler et al [15]) has evaluated the impact of maternal obesity and asthma on perinatal outcomes. In this study, obese asthmatic women were found to have babies with a higher mean birthweight than nonobese asthmatic women, but were not found to be at higher risk for preterm birth. This study did not consider SGA, a more precise measure of intrauterine growth, as an outcome, nor did it consider LGA, even if obesity is a known risk factor for this adverse perinatal outcome (15).

${ }^{1}$ Faculty of Pharmacy, Université de Montréal; ${ }^{2}$ Endowment Pharmaceutical Chair AstraZeneca in Respiratory Health; ${ }^{3}$ Research Centre of

Hôpital du Sacré-Cour de Montréal, Montréal, Québec

Correspondence: Dr Lucie Blais, Université de Montréal, Faculté de pharmacie, CP 6128, succursale Centre-ville, Montréal, Québec H3C 3J7.

Telephone 514-343-6111 ext 3786,fax 514-343-6120, e-mail lucie.blais@umontreal.ca 
Therefore, the objective of the present population-based cohort study was to evaluate the concomitant impact of maternal asthma and obesity on SGA as a primary outcome, and on LGA and preterm birth as secondary outcomes.

\section{METHODS}

\section{Study design}

The present study was based on a subcohort of a retrospective cohort of pregnancies from asthmatic women that has been described elsewhere and used to answer other research questions related to asthma and pregnancy (16-19). This cohort of 13,007 singleton pregnancies from 9925 asthmatic women who delivered between 1990 and 2002 was formed by the linkage of three administrative databases in Quebec (19). The database of the Régie de l'assurance maladie du Québec (RAMQ) contains information on medical services provided to all residents and prescribed medications filled in community pharmacies for residents covered by the RAMQ (public) drug insurance plan, which represents approximately $43 \%$ of the population. MED-ECHO is a database that records information on all acute care hospitalizations occurring in Quebec. This database also provides information on gestational age and birthweight for all births occurring in a hospital. The Fichier des événements démographiques is operated by the Institut de la statistique du Québec (ISQ) and records information on birth, stillbirth and parental demographic variables. Pregnancy-related variables, such as birthweight, gestational age, date of conception and delivery directly recorded or derived from the RAMQ, MED-ECHO and ISQ databases, have been evaluated in the past and found to be highly accurate and valid (20).

Pregnancies were included in the cohort if women were between 13 and 50 years of age at the beginning of pregnancy and covered by the RAMQ drug insurance plan for at least one year before and during pregnancy. Women were considered to have had asthma if they filled at least one prescription for an asthma medication and had at least one diagnosis of asthma (International Classification of Diseases, Ninth Revision codes 493 except 493.2) two years before or during pregnancy. Asthma diagnoses recorded in the RAMQ database have been evaluated and found to be valid (21). The RAMQ and the Commission d'accès à l'information du Québec granted authorization to contact by mail a sample of women included in the cohort to collect information on variables that are not recorded in the databases such as sibling history of asthma, maternal lifestyle during pregnancy, maternal height and weight, and weight gain during pregnancy. Questionnaires were mailed to 6422 asthmatic women, of which 2637 were received and analyzed in two previous studies $(18,19)$. It is worth noting that due to the design of the previous studies, which oversampled women who had a small baby or a preterm delivery, $46 \%$ of the women who returned a completed questionnaire had to be excluded from the present study so as to avoid selecting a biased subcohort.

The subcohort that was used in the present study was thus formed from a sample representative of the entire initial cohort with regard to the rate of SGA (14.4\%), and included 1337 women (1386 pregnancies, 49 women contributed two pregnancies) who returned a questionnaire with complete information on maternal prepregnancy weight and height, and did not have diabetes mellitus before pregnancy. Diabetic women were excluded because this chronic disease is a known risk factor for adverse perinatal outcomes (22) but affects too few underweight women and women with normal weight to be adjusted for at the analysis stage.

\section{Exposure, outcomes and potential confounders}

Mother's prepregnancy body mass index (BMI) was evaluated using self-reported information collected by the mailed questionnaire. The BMI was divided into four categories following the WHO recommendations: underweight (BMI $\left.<18.5 \mathrm{~kg} / \mathrm{m}^{2}\right)$, normal weight $\left(18.5 \mathrm{~kg} / \mathrm{m}^{2}\right.$ to $\left.\leq 25 \mathrm{~kg} / \mathrm{m}^{2}\right)$, overweight $\left(25.0 \mathrm{~kg} / \mathrm{m}^{2}\right.$ to $\left.<30 \mathrm{~kg} / \mathrm{m}^{2}\right)$ and obese women $\left(\mathrm{BMI} \geq 30.0 \mathrm{~kg} / \mathrm{m}^{2}\right)$.
The primary outcome was SGA, which is defined as a birthweight below the 10th percentile for gestational age and sex using Canadian standards (23). Among the secondary outcomes, LGA, defined as a birthweight above the 90th percentile for gestational age, and preterm birth, defined as a birth before the 37th week of gestation, were considered.

A total of 17 potentially confounding variables were classified into three categories. Maternal characteristics included age at the beginning of the pregnancy $(<18,18$ to $34,>34$ years of age), annual family income during pregnancy $(\leq \$ 18,000, \$ 18,001$ to $\$ 30,000,>\$ 30,000)$, receiving social assistance one year before or during pregnancy (yes/ no), living in a rural area during pregnancy (yes/no), being nullipara (yes/no) and the number of years of education attained at delivery ( 0 to 11,12 to $15, \geq 16$ years). Pregnancy-related variables included a high-risk pregnancy (yes/no), gestational diabetes (yes/no), pregnancyinduced hypertension (yes/no), at least one visit to the obstetrician or gynecologist (yes/no), number of perinatal visits $(\leq 5$, six to $14,>14)$, maternal weight gain during pregnancy according to the Canadian recommendations based on the mother's prepregnancy BMI (inferior, normal, superior [24]), low birth weight (LBW) infant or a preterm delivery before the current delivery, and delivery of a boy in the current delivery. Maternal lifestyle habits included cigarette smoking (yes/no) and alcohol consumption during pregnancy (yes/no).

\section{Use of asthma medications and health care services for asthma}

To describe the use of asthma medications and health care services, the following asthma-related variables were reported: the use of shortacting inhaled beta 2 -agonists $(0,>0$ to $3,>3$ to $10,>10$ doses per week), daily use of inhaled corticosteroids ( $\mu$ g of fluticasone-equivalent) during pregnancy $(0 \mu \mathrm{g},>0 \mu \mathrm{g}$ to $250 \mu \mathrm{g},>250 \mu \mathrm{g})$, use of at least one add-on controller therapy (long-acting beta 2 -agonists, antiallergic (cromolyn or nedocromil), leukotriene-receptor antagonists or theophylline) (yes/no), one or more filled short-course prescription of OCS (yes/no), one or more visit to the emergency department for asthma (yes/no), and one or more hospitalization for asthma (yes/no) during pregnancy. These variables were not considered to be potential confounders because obesity may act on them and an adjustment for such variables could have obscured an association between obesity and perinatal outcomes.

\section{Statistical analysis}

Descriptive statistics (frequencies and means) were used to describe the characteristics of the pregnancies included in the subcohort. The prevalence of the three perinatal outcomes according to the mother's prepregnancy BMI were also calculated. Missing data were present for five confounding variables retrieved from the questionnaire at a rate of $2.2 \%$ or less and the missing values were included in the category that was the most prevalent (see Appendix for more details). Moreover, a weight gain of $\geq 50 \mathrm{~kg}$ or a weight loss $\geq 30 \mathrm{~kg}$ during pregnancy was considered to be an outlier (25); these extreme values were replaced by the average weight gain or weight loss in the woman's BMI category.

Logistic regression models were used to estimate the crude and adjusted ORs for SGA, LGA and preterm birth comparing underweight, overweight and obese women with normal weight women. To find the final model for a specific outcome, the independent variables that were associated with this outcome with $\mathrm{P} \leq 0.1$ were retained. After that, all retained independent variables and the BMI were included in a model, and a backward selection strategy was used to find the final reduced model by gradually withdrawing variables that were not confounders on the BMI-outcome association (ie, did not change the ORs associated with BMI by $\geq 10 \%$ ) and were not significantly associated with the outcome under study $(\mathrm{P}>0.05)$. Ninety-five per cent $\mathrm{CIs}$ were calculated for adjusted $\mathrm{ORs}$ and all statistical analyses were performed using SPSS version 16.0 (IBM Corporation, USA).

Details of ethics approval

Approvals from the Ethics Board of the Hôpital du Sacré-Coeur de Montreal (Montreal, Quebec) (Approval number: 2009-10-85), and 
TABLE 1

Characteristics of all pregnancies included in the cohort as a function of the prepregnancy body mass index (BMI) ( $\mathrm{n}=1386)$

\begin{tabular}{|c|c|c|c|c|}
\hline \multirow[b]{2}{*}{ Variable } & \multicolumn{4}{|c|}{ BMI } \\
\hline & $\begin{array}{c}<18.5 \mathrm{~kg} / \mathrm{m}^{2} \\
(\mathrm{n}=149)\end{array}$ & $\begin{array}{c}18.5 \mathrm{~kg} / \mathrm{m}^{2} \text { to }<25.0 \mathrm{~kg} / \mathrm{m}^{2} \\
(\mathrm{n}=739)\end{array}$ & $\begin{array}{c}25.0 \mathrm{~kg} / \mathrm{m}^{2} \text { to }<30 \mathrm{~kg} / \mathrm{m}^{2} \\
(\mathrm{n}=273)\end{array}$ & $\begin{array}{c}\geq 30.0 \mathrm{~kg} / \mathrm{m}^{2} \\
(\mathrm{n}=225)\end{array}$ \\
\hline \multicolumn{5}{|l|}{ Maternal characteristics } \\
\hline$<18$ & $11(7.4)$ & $36(4.9)$ & $7(2.6)$ & $4(1.8)$ \\
\hline $18-34$ & $129(86.6)$ & $661(89.4)$ & $250(91.6)$ & $204(90.7)$ \\
\hline$>34$ & $9(6.0)$ & $42(5.7)$ & $16(5.9)$ & $17(7.6)$ \\
\hline 18,000 & $98(65.8)$ & $445(60.2)$ & $177(64.8)$ & $140(62.2)$ \\
\hline $18,001-30,000$ & $33(22.1)$ & $162(21.9)$ & $52(19.0)$ & $56(24.9)$ \\
\hline$>30,000$ & $18(12.1)$ & $132(17.9)$ & $44(16.1)$ & $29(12.9)$ \\
\hline Recipient of social assistance* & $128(85.9)$ & $519(70.2)$ & $199(72.9)$ & $165(73.3)$ \\
\hline Rural residency at delivery & $22(14.8)$ & $191(25.8)$ & $75(27.5)$ & $42(18.7)$ \\
\hline Nullipara & $72(48.3)$ & $279(37.8)$ & $86(31.5)$ & $69(30.7)$ \\
\hline \multicolumn{5}{|l|}{ Pregnancy-related variables } \\
\hline High-risk pregnancy & $50(33.6)$ & $260(35.2)$ & $89(32.6)$ & $94(41.8)$ \\
\hline Gestational diabetes & $8(5.4)$ & $52(7.0)$ & $29(10.6)$ & $42(18.7)$ \\
\hline Pregnancy-induced hypertension & $4(2.7)$ & $41(5.5)$ & $22(8.1)$ & $40(17.8)$ \\
\hline $\begin{array}{l}\text { At least one visit to the obstetrician or } \\
\text { gynecologist }\end{array}$ & $101(67.8)$ & $515(69.7)$ & $188(68.9)$ & $165(73.3)$ \\
\hline \multicolumn{5}{|l|}{ Number of prenatal visits } \\
\hline$\leq 5$ & $22(14.8)$ & $101(13.7)$ & $32(11.7)$ & $31(13.8)$ \\
\hline $6-14$ & $112(75.2)$ & $530(71.7)$ & $209(76.6)$ & $155(68.9)$ \\
\hline$>14$ & $15(10.1)$ & $108(14.6)$ & $32(11.7)$ & $39(17.3)$ \\
\hline \multicolumn{5}{|l|}{ Maternal weight gain during pregnancy ${ }^{\dagger}$} \\
\hline \multicolumn{5}{|l|}{ Lifestyle habits } \\
\hline Maternal cigarette smoking during pregnancy & $122(81.9)$ & $485(65.6)$ & $174(63.7)$ & $144(64.0)$ \\
\hline $\begin{array}{l}\text { Maternal alcohol consumption during } \\
\text { pregnancy }\end{array}$ & $36(24.2)$ & $162(21.9)$ & $48(17.6)$ & $29(12.9)$ \\
\hline \multicolumn{5}{|c|}{ Asthma-related variables measured during pregnancy } \\
\hline \multicolumn{5}{|c|}{ Use of SABA, doses per week } \\
\hline 0 & $56(37.6)$ & $241(32.6)$ & $78(28.6)$ & $63(28.0)$ \\
\hline$>0-3$ & $39(26.2)$ & $213(28.8)$ & $83(30.4)$ & $61(27.1)$ \\
\hline$>3-10$ & $41(27.5)$ & $180(24.4)$ & $71(26.0)$ & $68(30.2)$ \\
\hline$>10$ & $13(8.7)$ & $105(14.2)$ & $41(15.0)$ & $33(14.7)$ \\
\hline \multicolumn{5}{|l|}{ Daily use of ICS (fluticasone-equivalent), $\mu \mathrm{g}$} \\
\hline 0 & $96(64.4)$ & $402(54.4)$ & $135(49.5)$ & $103(45.8)$ \\
\hline$>0-250$ & $50(33.6)$ & $309(41.8)$ & $126(46.2)$ & $110(48.9)$ \\
\hline$>250$ & $3(2.0)$ & $28(3.8)$ & $12(4.4)$ & $12(5.3)$ \\
\hline Use of at least one add-on controller therapy ${ }^{\ddagger}$ & $10(6.7)$ & $31(4.2)$ & $18(6.6)$ & $14(6.2)$ \\
\hline $\begin{array}{l}\geq 1 \text { filled short-course prescription of } \\
\text { oral corticosteroids }\end{array}$ & $11(7.4)$ & $63(8.5)$ & $25(9.2)$ & $26(11.6)$ \\
\hline$\geq 1$ emergency department visit for asthma & $23(15.4)$ & $120(16.2)$ & $48(17.6)$ & $40(17.8)$ \\
\hline$\geq 1$ hospitalization for asthma & $2(1.3)$ & $8(1.1)$ & $4(1.5)$ & $3(1.3)$ \\
\hline
\end{tabular}

Data presented as $n(\%)$ unless otherwise indicated. ${ }^{*}$ Receipt of social assistance in the year before or during pregnancy; ${ }^{\dagger}$ According to the Canadian recommendations based on the mother's prepregnancy BMI; ${ }^{\ddagger}$ Long-acting beta ${ }_{2}$-agonists, anti-allergic medication, leukotriene antagonists or theophylline. ICS Inhaled corticosteroids; SABA Short-acting inhaled beta $_{2}$-agonists 
TABLE 2

Prevalence of adverse perinatal outcomes as a function of the mother's body mass index (BMI) among women with asthma

\begin{tabular}{llccc}
\hline & \multicolumn{4}{c}{ BMI, $\mathbf{~ k g} / \mathbf{m}^{\mathbf{2}}$} \\
\cline { 2 - 5 } & $<\mathbf{1 8 . 5}$ & $\mathbf{1 8 . 5}$ to $<\mathbf{2 5 . 0}$ & $\mathbf{2 5 . 0}$ to $<\mathbf{3 0}$ & $\mathbf{2 3 0 . 0}$ \\
\hline $\begin{array}{l}\text { Pregnancies, } \mathrm{n} \\
\text { Perinatal }\end{array}$ & 149 & 739 & 273 & 225 \\
outcomes & \multicolumn{5}{c}{ Cases, $\mathbf{n}$ (\%) } \\
\hline SGA & $35(23.5)$ & $118(16.0)$ & $32(11.7)$ & $19(8.4)$ \\
LGA & $35(2.7)$ & $45(6.1)$ & $14(5.1)$ & $22(9.8)$ \\
Preterm birth & $14(9.4)$ & $82(11.0)$ & $18(6.6)$ & $21(9.3)$ \\
\hline
\end{tabular}

SGA Small for gestational age; LGA Large for gestational age

the Commission d'accès à l'information du Québec were obtained beforeproceeding with the study.

\section{RESULTS}

A total of 1386 singleton pregnancies from 1337 asthmatic mothers were included in the subcohort including $11 \%$ underweight, $53 \%$ normal weight, $20 \%$ overweight and $17 \%$ obese women before their pregnancy. Baseline characteristics are summarized in Table 1. Underweight women were younger, more likely to receive social assistance, more often nulliparous, had a lower level of education, more likely to have given birth to a LBW infant in a previous pregnancy and were more likely to smoke. On the other hand, obese women were more likely to have a high-risk pregnancy, gestational diabetes and pregnancy-induced hypertension. Moreover, they were more likely to gain more weight during pregnancy than what is recommended by Health Canada (24). Underweight women used fewer short-acting beta ${ }_{2}$-agonists, and obese women used more inhaled corticosteroids and OCS, and went to the emergency department for asthma slightly more often.

The prevalence of the outcomes as a function of BMI are presented in Table 2. The prevalence of SGA babies was found to be inversely related to the mother's BMI, being $23.5 \%$ for underweight and $8.4 \%$ for obese women. On the other hand, it was found that the prevalence of LGA babies tended to increase (but again not perfectly) with increasing BMI. Surprisingly, normal-weight women had the highest risk of preterm birth, followed by underweight, obese and overweight women.

As shown in Table 3, the adjusted analysis revealed that obese asthmatic women were not more at risk of giving birth to a SGA baby than normal-weight asthmatic women (adjusted OR $0.6[95 \%$ CI 0.4 to 1.1]). Underweight and overweight women were not significantly more at risk to give birth to an SGA baby. This logistic regression model also showed that women $<18$ years of age, those who were nulliparous, women who had a history of LBW infants and those who smoked were significantly more at risk, while women who gained more weight than what is recommended by Health Canada and those who had a history of premature infant birth were significantly less at risk of giving birth to an SGA baby.

As shown in Table 4, no significant associations between BMI and LGA, or between BMI and preterm birth were observed. Despite these nonsignificant results, an increasing trend of LGA babies with increasing BMI was observed.

\section{DISCUSSION}

The results of our study revealed that obese asthmatic women were not at increased risk of giving birth to an SGA or LGA baby, nor were they more at risk of having a preterm delivery than normal-weight asthmatic women. These results do not support our hypothesis that women with asthma and obesity are at an increased risk of adverse perinatal outcomes. The absence of a double-negative impact of obesity and asthma on perinatal outcomes is reassuring.

TABLE 3

Impact of prepregnancy body mass index (BMI) on the risk of a small-for-gestational-age baby among women with asthma

\begin{tabular}{lcc}
\hline \multirow{2}{*}{ Variable } & \multicolumn{2}{c}{ OR (95\% Cl) } \\
\cline { 2 - 3 } Maternal characteristic & Crude & Adjusted* \\
Prepregnancy BMI, kg/m² & & \\
$\quad<18.5$ & $\mathbf{1 . 6}(\mathbf{1 . 1}-\mathbf{2 . 5})$ & $1.3(0.8-2.0)$ \\
18.5 to $<25.0$ & Reference & Reference \\
25.0 to $<30$ & $0.7(0.5-1.1)$ & $0.9(0.6-1.4)$ \\
$\geq 30.0$ & $\mathbf{0 . 5}(\mathbf{0 . 3}-\mathbf{0 . 8 )}$ & $0.6(0.4-1.0)$
\end{tabular}

Maternal age at the beginning of pregnancy, years

$<18$

$18-34$

$>34$

Annual family income, \$

$\leq 18,000$

$18,001-30,000$

$>30,000$

Recipient of social assistance ${ }^{\dagger}$

Rural residency at delivery

Nullipara

2.6 (1.4-4.7)

Reference

$1.4(0.8-2.4)$

$2.2(1.2-4.2)$

Reference

$1.3(0.7-2.4)$

Number of

$$
\text { 0-11 }
$$

12-15

$\geq 16$

Pregnancy-related variables

High-risk pregnancy

Gestational diabetes

Pregnancy-induced hypertension

At least one visit to the obstetrician or gynecologist

Number of prenatal visits

$\begin{array}{lcc}\leq 5 & 1.0(0.7-1.6) & \text { NR } \\ 6-14 & \text { Reference } & \text { Reference } \\ >14 & 0.8(0.5-1.2) & \text { NR }\end{array}$

Maternal weight gain during pregnancy ${ }^{\ddagger}$

Normal

Inferior

Reference

Superior

$1.7(1.2-2.6)$

$0.6(0.4-0.9)$

Low birth weight infant before

the current delivery

Premature infant before

the current delivery

Delivery of a male infant in the

current delivery

Lifestyle habits

Maternal cigarette smoking during pregnancy

Maternal alcohol consumption during pregnancy

$2.3(1.6-3.5)$

$0.9(0.6-1.5)$

$1.1(0.8-1.4)$

Reference

$1.5(1.0-2.3)$

$0.6(0.4-0.8)$

$3.7(2.1-6.4)$

$0.4(0.2-0.8)$

NR

Bolded values indicate statistical significance. *Adjusted for maternal age at the beginning of pregnancy, nullipara, maternal weight gain during pregnancy, low birth weight infant before the current delivery and maternal cigarette smoking during pregnancy; ${ }^{\dagger}$ Receipt of social assistance in the year before or during pregnancy; ${ }^{\ddagger}$ According to the Canadian recommendations based on the mother's prepregnancy BMI. NR Not retained

Asthmatic women have been shown to be at increased risk of giving birth to SGA babies (3). This association can be explained by maternal uncontrolled asthma inducing hypoxia and respiratory 
alkalosis that decrease placental blood flow, which can reduce oxygen to the fetus and affect fetal growth (26). Furthermore, hypoxia apparent in asthma exacerbation or severe asthma may also increase the inflammatory state and cause cortisol liberation. This hormone could be responsible for growth retardation and decrease of placental blood flow (26). However, our results suggest that the effect of asthma may be overridden by the effect of obesity, and other mechanisms can explain the protective effect of obesity on SGA, an effect that has been described in some studies investigating general populations of pregnant women $(10,27)$. In fact, pregnancy is characterized as an insulin-resistant condition, with an increase of almost 50\% in insulin resistance during pregnancy among normal weight women (27). Also, maternal prepregnancy weight is strongly correlated with insulin sensitivity and fetal growth (27). Furthermore, in obese women, placental dysfunction that increases the availability of glucose, free fatty acids and amino acids may be present (27). Therefore, there would be more risk for impaired glucose tolerance (and/or prediabetes) among obese pregnant women and it is known that diabetes increases the risk of macrosomia (28).

Our study is is not comparable with others because it was the first to evaluate the combined effect of asthma and obesity on the risk of SGA. However, preterm birth in asthmatic obese women has been studied by Hendler et al (15), who divided pregnant women into obese $\left(\mathrm{BMI} \geq 30 \mathrm{~kg} / \mathrm{m}^{2}\right)$ and nonobese $\left(\mathrm{BMI}<30 \mathrm{~kg} / \mathrm{m}^{2}\right)$ categories. Similar to our results, they found a nonsignificant reduced risk of preterm birth among 521 obese asthmatic women compared with nonobese asthmatic women, suggesting again that the effect of asthma on preterm delivery is overridden by the effect of obesity (15). A possible mechanism that explains the protective effect of obesity on preterm delivery relates to leptin (an adipose-derived hormone), which inhibits the onset of spontaneous uterine activity and is found in higher levels in obese women compared with nonobese women (29). Hendler et al (15) did not study the risk of LGA babies, but they observed that babies from obese asthmatic women had a mean birthweight higher than babies from nonobese asthmatic women (mean $[ \pm$ SD] weight $3117 \pm 748 \mathrm{~g}$ versus $3107 \pm 653 \mathrm{~g}$ ). These results were statistically significant $(\mathrm{P}=0.001)$ but not clinically significant according to the authors.

Furthermore, in our study, we found a trend toward a higher risk of LGA among asthmatic obese women, suggesting that obese women give birth to babies that are heavier than babies born to normal weight asthmatic women. Khashan and Kenny (9), and Lu et al (30) found a higher risk of LGA among obese women regardless of the presence of asthma (RR 1.63 [95\% CI 1.51 to 1.77 ] and RR 2.2 [95\% CI 1.9 to 2.4], respectively). These two studies, as well as many others, also reported an increased risk of macrosomia among obese women $(9-12,30)$

Our study has several strengths. To our knowledge, the present study was the first to evaluate the risk for SGA infants among asthmatic and obese pregnant women. Also, by using administrative databases, we were able to obtain a relatively large sample of pregnancies in asthmatic women. The statistical analysis allowed the inclusion of several potential confounding variables, reducing the risk of residual confounding bias. Finally, SGA and LGA were calculated using new Canadian standards, and the measure of gestational age recorded in the databases has been formally analyzed and found to be highly valid $(20,23)$

A few limitations, however, should be kept in mind when interpreting the results. A nondifferential measurement error may be present for height and weight of the mother because they were selfreported; it is documented that people tend to overestimate their height and underestimate their weight (31). Consequently, the BMI calculated from self-reported height and weight may have been lower than it actually was. Also, despite the fact that we measured several potential confounders, we cannot completely rule out the possibility of residual confounding due to the observational nature of the study design. Post hoc power calculations revealed that our study had $80 \%$
TABLE 4

Impact of pre-pregnancy body mass index (BMI) on the risk of a large-for-gestational-age (LGA) baby and preterm birth among women with asthma

\begin{tabular}{lcc}
\hline & \multicolumn{2}{c}{ OR (95\% Cl) } \\
\cline { 2 - 3 } & \multicolumn{1}{c}{ LGA $^{*}$} & Preterm birth \\
\hline & & \\
$<18.5$ & $0.5(0.2-1.5)$ & $0.7(0.4-1.2)$ \\
18.5 to $<25.0$ & \multicolumn{2}{c}{ Reference } \\
25.0 to $<30$ & $0.7(0.3-1.2)$ & $0.6(0.3-1.1)$ \\
$\geq 30.0$ & $1.2(0.7-2.1)$ & $0.7(0.4-1.2)$ \\
\hline
\end{tabular}

*Adjusted for number of years of education attained at delivery, nullipara, gestational diabetes and maternal weight during pregnancy; ${ }^{\dagger}$ Adjusted for highrisk pregnancy, pregnancy induced hypertension, number of prenatal visits, maternal weight gain during pregnancy, premature infant before current delivery and maternal cigarette smoking during pregnancy

power to detect an OR of 1.6 for SGA infants, an OR of 2.1 for LGA infants and an OR of 1.8 for preterm delivery when comparing obese with normal weight women. This implies that smaller associations could have been missed due to a lack of power. Finally, our cohort was less representative of women with higher socioeconomic status because all of the women included in our cohort were covered by the public drug insurance plan.

\section{CONCLUSION}

In the present study, we observed that obese asthmatic women were not at a higher risk for perinatal outcomes than normal-weight asthmatic women. We found no negative interaction between maternal asthma and obesity on the growth of the fetus. These results are reassuring for obese asthmatic women; however, pregnant women should be encouraged to follow the recommendations for weight gain during pregnancy to avoid adverse outcomes related to overweight and obesity.

\section{Analysis for missing data}

\section{APPENDIX}

Missing values were present in a low proportion for five potential confounding variables: annual family outcome (2.0\%); parity $(0.2 \%)$; weight gain during pregnancy $(1.4 \%)$; LBW infant before the present delivery $(0.3 \%)$; alcohol consumption during pregnancy $(2.2 \%)$; and highest level of education attained (2.2\%). All missing values, except for weight gain during pregnancy, were included in the most prevalent category: 0 to 11 years for the highest level of education attained, $\leq \$ 18,000$ for the income, nullipara for the parity, no-LBW for LBW infant before the current delivery and no alcohol for maternal alcohol consumption. For weight gain during pregnancy, the average weight gain of the corresponding category of BMI were attributed to the missing values.

ACKNOWLEDGEMENTS: Institution from which the work originated: Université de Montréal, Faculty of Pharmacy, Montréal, Québec. Meggie Thuot, Marc-André Coursol Tellier, Sonia Nguyen, Vanessa Lacasse-Guay, Marie-France Beauchesne, Anne Fillion and Lucie Blais contributed to the conception and design of the study. Meggie Thuot, Marc-André Coursol Tellier, Sonia Nguyen and Vanessa Lacasse-Guay performed the literature review. Amélie Forget contributed to the acquisition of data and supervised the analysis of data. Meggie Thuot and MarcAndré Coursol Tellier performed the analysis of the data. The results were interpreted by Meggie Thuot, Marc-André Coursol Tellier, Marie-France Beauchesne, Anne Fillion and Lucie Blais. Meggie Thuot and Marc-André Coursol Tellier drafted the manuscript. All authors crtically revised the manuscript for important intellectual content and gave final approval of the version to be published. The authors thank Mrs Marie-Claude Giguère from the Régie de l'Assurance maladie du Québec, Mrs Chantal Girouard from the Institut de la statistique du Québec and Mrs Louise Légaré and col- 
laborators from the Ministère de la Santé et des Services sociaux du Québec for assistance with the data. They are grateful to the Commission d'accès à l'information du Québec for authorizing the study. They also thank Mrs Karine Chouinard from the University of Montréal for helping with logistics of the study. Finally, many thanks to all women who kindly participated in this study by completing the questionnaire.

\section{REFERENCES}

1. Kwon HL, Triche EW, Belanger K, Bracken MB. The epidemiology of asthma during pregnancy: Prevalence, diagnosis, and symptoms. Immunol Allergy Clin N Am 2006;26:29-62.

2. Robinson HE, O'Connell CM, Joseph KS, McLeod NL. Maternal outcomes in pregnancies complicated by obesity. Obstet Gynecol 2005;106:1357-64.

3. Murphy V, Namazy J, Powell H, et al. A meta-analysis of adverse perinatal outcomes in women with asthma. BJOG 2011;118:1314-23.

4. Bakhireva LN, Schatz M, Jones KL, Chambers CD. Asthma control during pregnancy and the risk of preterm delivery or impaired fetal growth. Ann Allergy Asthm Immunol 2008;101:137-43.

5. Schatz M, Dombrowski MP, Wise R, et al. Spirometry is related to perinatal outcomes in pregnant women with asthma. Am J Obstet Gynecol 2006;194:120-6.

6. Murphy VE, Clifton VL, Gibson PG. Asthma exacerbations during pregnancy: Incidence and association with adverse pregnancy outcomes. Thorax 2006;61:169-76.

7. Bracken MB, Triche EW, Belanger K, Saftlas A, Beckett WS, Leaderer BP. Asthma symptoms, severity, and drug therapy: A prospective study of effects on 2205 pregnancies. Obstet Gynecol 2003;102:739-52.

8. Dombrowski M, Schatz M, Wise R, et al. Asthma during pregnancy. Obstet Gynecol 2004;103:5-12.

9. Khashan AS, Kenny LC. The effects of maternal body mass index on pregnancy outcome. Eur J Epidemiol 2009;24:697-705.

10. Abenhaim HA, Kinch RA, Morin L, Benjamin A, Usher R. Effect of prepregnancy body mass index categories on obstetrical and neonatal outcomes. Arch Gynecol Obstet 2007;275:39-43.

11. Bhattacharya S, Campbell DM, Liston WA, Bhattacharya S. Effect of body mass index on pregnancy outcomes in nulliparous women delivering singleton babies. BMC Public Health 2007;7:168.

12. Dixit A, Girling JC. Obesity and pregnancy. J Obstet Gynaecol 2008;28:14-23.

13. Saint-Pierre P, Bourdin A, Chanez P, Daures JP, Godard P. Are overweight asthmatics more difficult to control? Allergy 2006;61:79-84.

14. Lavoie KL, Bacon SL, Labrecque M, Cartier A, Ditto B. Higher BMI is associated with worse asthma control and quality of life but not asthma severity. Respir Med 2006;100:648-57.

15. Hendler I, Schatz M, Momirova V, et al. Association of obesity with pulmonary and nonpulmonary complications of pregnancy in asthmatic women. Obstet Gynecol 2006;108:77-82.

16. Firoozi F, Lemiere C, Beauchesne MF, Perreault S, Forget A, Blais L. Impact of maternal asthma on perinatal outcomes: A two-stage sampling cohort study. Eur J Epidemiol 2012;27:205-14.

17. Breton MC, Beauchesne MF, Lemiere C, Rey E, Forget A, Blais L. Risk of perinatal mortality associated with asthma during
FUNDING SOURCE: This study was funded through a grant from the Canadian Institutes for Health Research.

DISCLOSURES: The authors have no financial disclosures or conflicts of interest to declare.

pregnancy: A 2-stage sampling cohort study. Ann Allergy Asthma Immunol 2010;105:211-7.

18. Martel MJ, Rey E, Malo JL, et al. Determinants of the incidence of childhood asthma: A two-stage case-control study. Am J Epidemiol 2009;169:195-205.

19. Martel MJ, Rey E, Beauchesne MF, et al. Control and severity of asthma during pregnancy are associated with asthma incidence in offspring: Two-stage case-control study. Eur Respir J 2009;34:579-87.

20. Vilain A, Otis S, Forget A, Blais L. Agreement between administrative databases and medical charts for pregnancy-related variables among asthmatic women. Pharmacoepidemiol Drug Saf 2008; 17:345-53.

21. Blais L, Lemière C, Menzies D, Berbiche D. Validity of asthma diagnoses recorded in the Medical Services database of Quebec. Pharmacoepidemiol Drug Saf 2006;15:245-52.

22. Sibai BM, Caritis SN, Hauth JC, et al. Preterm delivery in women with pregestational diabetes mellitus or chronic hypertension relative to women with uncomplicated pregnancies. The National institute of Child health and Human Development Maternal-Fetal Medicine Units Network. Am J Obstet Gynecol 2000;183:1520-4.

23. Kramer MS, Platt RW, Wen SW, et al. A new and improved population-based Canadian reference for birth weight for gestational age. Pediatrics 2001;108:35.

24. Santé Canada. Canadian Gestational Weight Gain Recommendations. <www.hc-sc.gc.ca/fn-an/nutrition/prenatal/ qa-gest-gros-qr-eng php> (Accessed January 19, 2010).

25. Beyerlein A, Schiessl B, Lack N, von KR. Optimal gestational weight gain ranges for the avoidance of adverse birth weight outcomes: A novel approach. Am J Clin Nutr 2009;90:1552-8.

26. Murphy VE, Gibson PG, Smith R, Clifton VL. Asthma during pregnancy: Mechanisms and treatment implications. Eur Respir J 2005;25:731-50.

27. Yogev Y, Catalano PM. Pregnancy and obesity. Obstet Gynecol Clin N Am 2009;36:285-300, viii.

28. Jolly MC, Sebire NJ, Harris JP, Regan L, Robinson S. Risk factors for macrosomia and its clinical consequences: A study of 350,311 pregnancies. Eur J Obstet Gynecol Reproduct Biol 2003;111:9-14.

29. Moynihan AT, Hehir MP, Glavey SV, Smith TJ, Morrison JJ. Inhibitory effect of leptin on human uterine contractility in vitro. Am J Obstet Gynecol 2006;195:504-9.

30. Lu GC, Rouse DJ, DuBard M, Cliver S, Kimberlin D, Hauth JC. The effect of the increasing prevalence of maternal obesity on perinatal morbidity. Am J Obstet Gynecol 2001;185:845-9.

31. Gorber SC, Tremblay M, Moher D, Gorber B. A comparison of direct vs. self-report measures for assessing height, weight and body mass index: A systematic review. Obes Rev 2007;8:307-26. 


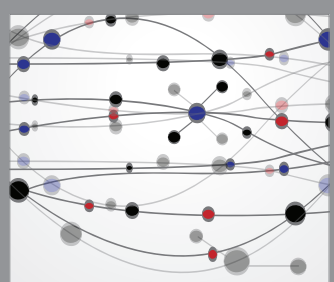

The Scientific World Journal
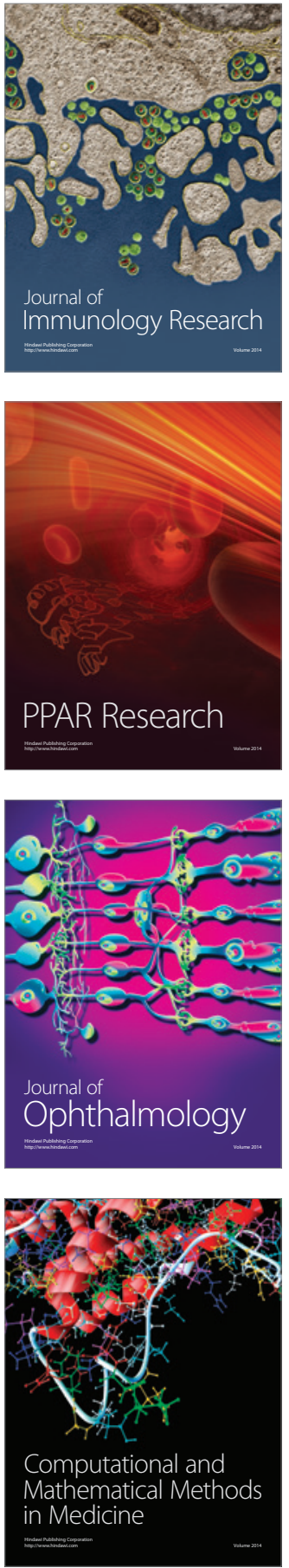

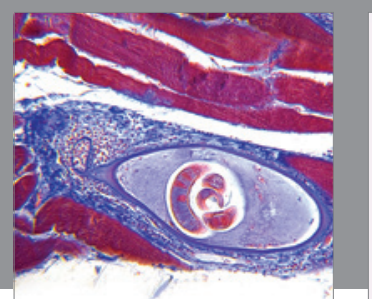

Gastroenterology Research and Practice

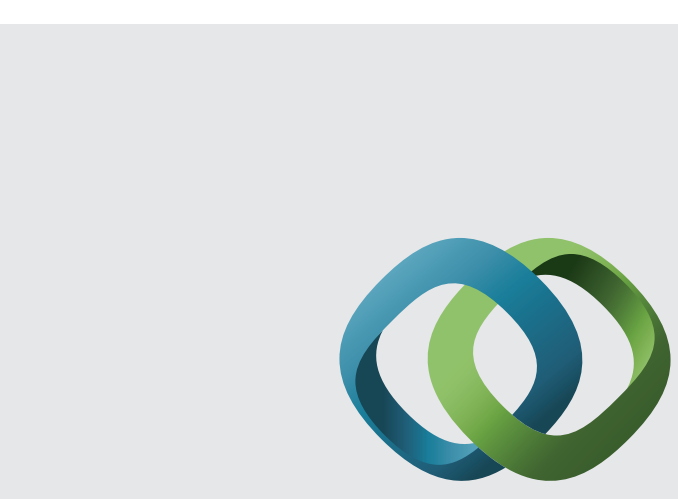

\section{Hindawi}

Submit your manuscripts at

http://www.hindawi.com
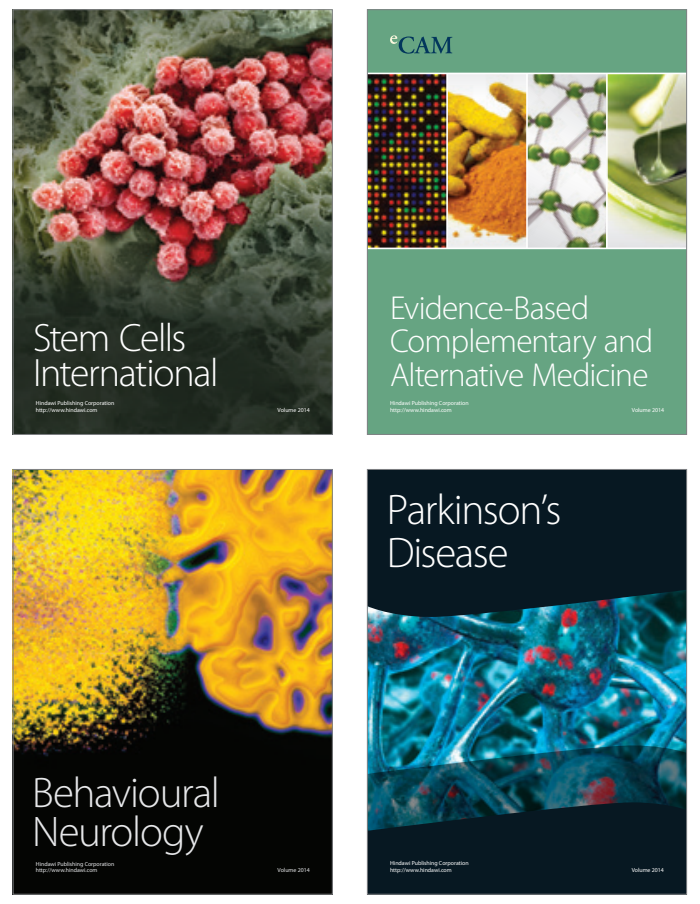
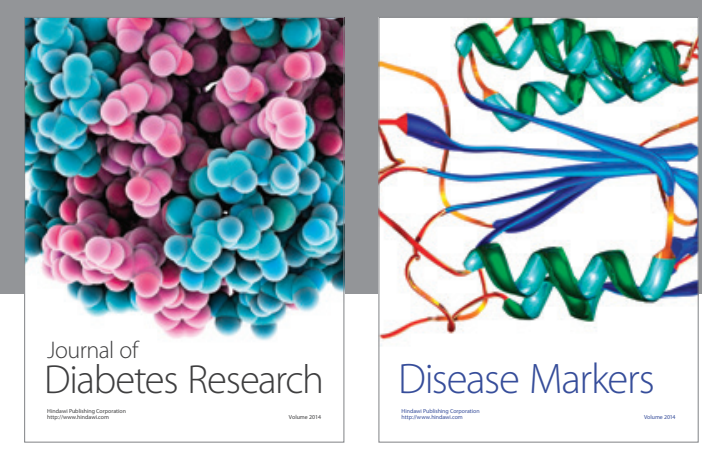

Disease Markers
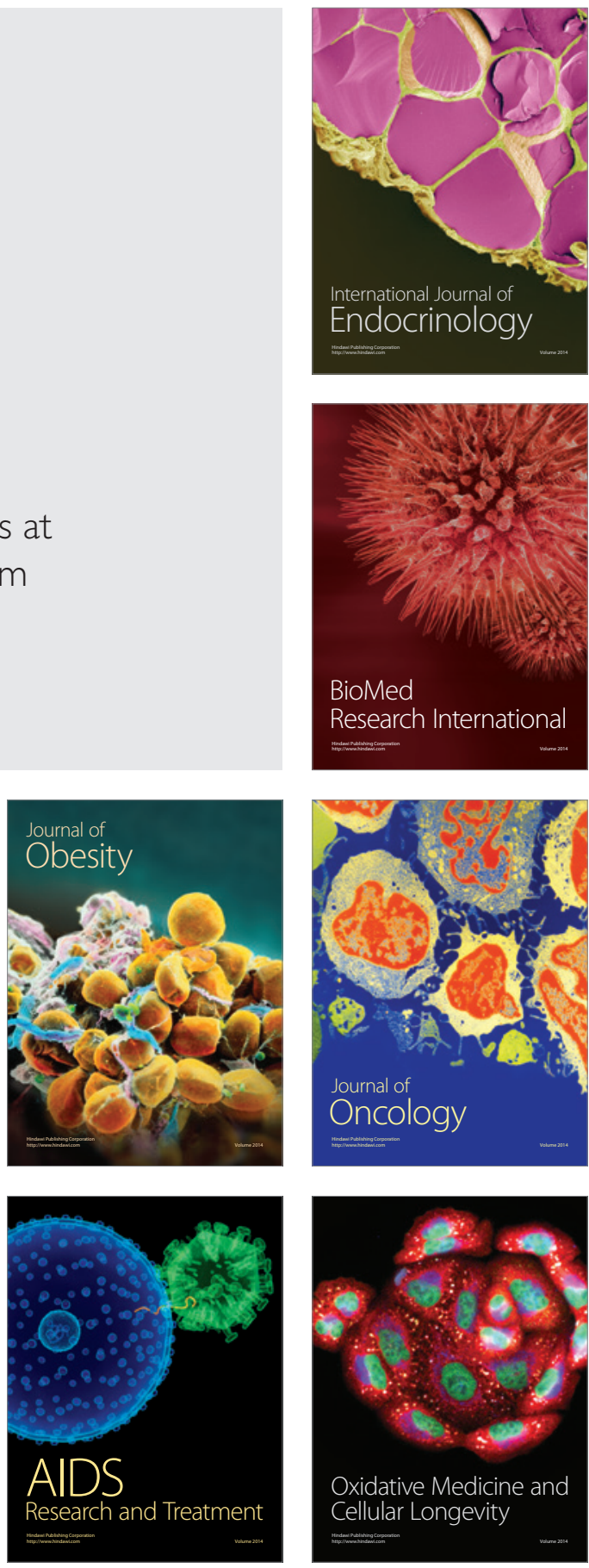